\title{
An auto-continuous positive airway pressure device controlled exclusively by the forced oscillation technique
}

\author{
J.H. Ficker, F.S. Fuchs, G.H. Wiest, G. Asshoff, A.H. Schmelzer, E.G. Hahn
}

\begin{abstract}
An auto-continuous positive airway pressure device controlled exclusively by forced oscillation technique. J.H. Ficker, F.S. Fuchs, G.H. Wiest, G. Asshoff, A.H. Schmelzer, E.G. Hahn. C) ERS Journals Ltd 2000.

ABSTRACT: The forced oscillation technique (FOT) has been demonstrated to be a very sensitive tool for the assessment of upper airway obstruction during nasal continuous positive airway pressure (CPAP) therapy for obstructive sleep apnoea (OSA). The present study was designed to evaluate the therapeutic efficacy of a novel auto-CPAP device based exclusively on the FOT.

Following manual CPAP titration, 18 patients with OSA (mean apnoea/hypopnoea index (AHI) 48.0 \pm 28.1 ) were allocated to conventional CPAP and auto-CPAP treatment under polysomnographic control in randomized order. The patients were asked to assess their subjective daytime sleepiness using the Epworth Sleepiness Scale (ESS).

The mean AHI during auto-CPAP treatment was $3.4 \pm 3.4$ and was comparable with that obtained during conventional CPAP treatment (4.2 \pm 3.6$)$. The analysis of sleep architecture, the arousal index $(6.6 \pm 2.1$ versus $7.3 \pm 4.4)$ or the ESS $(5.6 \pm 1.8$ versus $7.3 \pm 4.4)$ did not reveal any significant differences. However, the mean CPAP pressure during auto-CPAP treatment $(0.84 \pm 0.26 \mathrm{kPa})$ and in particular the pressure applied in the lateral body position $(0.74 \pm 0.35 \mathrm{kPa})$, was significantly lower than that employed in conventional CPAP treatment $(0.93 \pm 0.16 \mathrm{kPa}$, both comparisons: $p<0.05)$.

The auto-continuous positive airway pressure device proved equally as effective as conventional continuous positive airway pressure. However, the mean treatment pressure was significantly reduced, especially when patients were sleeping in the lateral position.
\end{abstract}

Eur Respir J 2000; 16: 914-920.

Nasal continuous positive airway pressure therapy (CPAP) is the most efficient and most widely used treatment for obstructive sleep apnoea syndrome (OSA). During standard CPAP-therapy, air at a constant elevated pressure is applied via a nasal mask. This effective pressure $(P$ eff $)$ is propagated through the nose into the pharynx where, acting as a "pneumatic splint", it prevents the airway from collapsing when it is set high enough to exceed the actual critical closing pressure of the upper airways (Pcrit) [1]. Pcrit and as a consequence, Peff, is dependant on many factors, such as body position, sleep stage and nasal obstruction, all of which may vary during the night. Furthermore, variations in patient weight, sleep deprivation or the use of alcohol, hypnotics or sedatives may contribute to changes in $P$ eff over time [2-4]. Some studies have reported that $P$ eff decreases somewhat during the first months after the start of therapy [5]. Thus $P$ eff must not be considered to be a constant, but may be highly variable in some patients.

To counter the variability of $P$ eff, self-adjusting CPAP machines (auto-CPAP) were developed to automatically match the treatment pressure to the patient's actual needs. An auto-CPAP device, capable of always increasing the CPAP pressure to a level high enough to abolish all symptoms of upper airway obstruction, should be able to achieve an optimum treatment quality during long-term
Medical Dept 1, University of ErlangenNuremberg, Erlangen, Germany.

Correspondence: J.H. Ficker

Medical Dept 1

University of Erlangen-Nuremberg

Krankenhausstr. 12

91054 Erlangen

Germany

Fax: 4991318536909

Keywords: Auto-continuous positive airway pressure

forced oscillation technique

nasal continuous positive airway pressure therapy

positive-pressure respiration

sleep apnoea syndromes

Received: December 271999

Accepted after revision July 252000

This study was supported by a grant from the Wilhelm-Sander-Stiflung, Neustadt an der Donau to J.H. Ficker (90.009.3). treatment, even when the patients actual Pcrit would exceed the $P$ eff established before during CPAP titration in the sleep laboratory. By theory, such a machine should reduce the mean CPAP pressure at least in patients with a high intra-night variability of $P$ eff, and could thus reduce pressure-associated side effects. This, in turn, would presumably improve patient acceptance. In addition, the use of auto-CPAP devices could help to reduce the cost and effort for CPAP titrations in the sleep laboratory and for follow-up [6].

Auto-CPAP machines are usually controlled by algorithms depending on flow measurements and/or pressure signals. Recently the forced oscillation technique (FOT) has been demonstrated to be a very sensitive tool for the assessment of dynamic upper airway obstruction during CPAP therapy and may be used for CPAP titration [7-12]. With this in mind a prototype of a novel auto-CPAP device which is (to the authors knowledge) the first one being controlled exclusively by FOT was studied (Somnosmart $\mathbb{R}$, Weinmann GmbH, Hamburg, Germany).

The present study was designed to establish the therapeutic efficacy of this novel auto-CPAP device, used without any individual adjustments, in comparison with a conventional constant-pressure CPAP machine set to the $P$ eff established by manual CPAP titration in the sleep laboratory. A particular aim was to test the hypothesis, that 
a well-performing auto-CPAP device should be able to reduce the mean treatment pressure at least in a majority of patients without compromising therapeutic effectiveness.

\section{Methods}

\section{Subjects}

The authors investigated 18 untreated patients with mild-to-severe obstructive sleep apnoea. To confirm the diagnosis, all the patients underwent a polysomnographic investigation in the sleep laboratory, and a subjective evaluation of daytime sleepiness was obtained using the Epworth Sleepiness Scale (ESS) [13]. Only those patients with an apnoea/hypopnoea index (AHI) of at least $10 \cdot \mathrm{h}^{-1}$, and an ESS score of $\geq 10$ were admitted to the study. All patients with a central sleep apnoea syndrome or CheyneStokes respiration, patients with contraindications for CPAP treatment [14], those who had already been treated with CPAP, those who had undergone previous velopharyngeal surgery, those with clinically manifest nasal obstruction, severe chronic obstructive pulmonary disease (COPD) (FEV1 $<70 \%$ pred), asthma or cardiac disease (NYHAFC $\geq \mathrm{II}$ ), and those who rejected CPAP or refused their consent to participate were excluded from the study.

\section{Sleep studies}

The diagnostic polysomnographies were performed in the sleep laboratory by trained sleep laboratory technicians. All variables were recorded on a computer (SleepLab, Jaeger and Toennies, Wurzburg, Germany), and included electroencephalography (EEG) (C4/A1, C3/A2), bilateral electro-oculography (EOG), submental and pretibial electromyography (EMG), nasal airflow measured by oronasal thermistors, snoring detected by microphone, electrocardiography (ECG), thoracic and abdominal movements measured by inductive plethysmography and oxyhaemoglobin saturation using a finger oximeter (Microspan 3040G, Jaeger and Toennies, Wurzburg, Germany). For CPAP titrations and for the CPAP study nights, flow was measured by a pneumotachograph (Weinmann, Hamburg, Germany) attached to the nasal mask and CPAP was measured continuously at the nasal mask. During the study nights, a $20 \mathrm{~Hz}$-filter was applied to the flow signals to remove the oscillations caused by the FOT unit. Obstructive apnoeas were defined as the absence of oronasal airflow for at least $10 \mathrm{~s}$. During diagnostic polysomnography hypopnoeas were defined as a reduction in thoracoabdominal movement amplitude to $\leq 50 \%$ of the preceding stable baseline for $10 \mathrm{~s}$ or longer [15]. During nasal CPAP therapy hypopnoeas were defined as a reduction in nasal airflow amplitude (measured by a pneumotachograph) to $\leq 60 \%$ of the preceding stable baseline for $10 \mathrm{~s}$ or longer. The mean number of apnoeas and hypopnoeas per hour of sleep was calculated as the apnoea/hypopnoea index (AHI). Sleep parameters were determined using the criteria of RECHTSCHAFFEN and KALES [16], and arousals were defined in accordance with the definitions of the American Sleep Disorders Association (ASDA) [17].
Continuous positive airway pressure machines employed

The auto-CPAP device studied was a prototype of the Somnosmart $\mathbb{R}$ (Weinmann, Hamburg, Germany) which is commercially available to date. It employs a servocontrolled turbine, and provides a CPAP of $0.4-1.8 \mathrm{kPa}$. The treatment pressure is controlled by an algorithm based exclusively on a simplified FOT; a membrane pump generates a sinusoidal signal at a constant frequency of $20 \mathrm{~Hz}$. This membrane pump is connected to the CPAP system at the nasal mask via a rubber tube. The pressure inside the nasal mask is measured via another rubber tube connected to a piezoresistive transducer inside the CPAP device, and the pressure signal is filtered by a $20 \mathrm{~Hz}$ band-pass to isolate the forced oscillation components. Changes in the amplitude of this FOT-signal are considered to represent changes in upper airway impedance $(Z)$. The physiological principles of this simplified FOT have been recently discussed elsewhere $[10,12,18,19]$. After starting the auto-CPAP device, a constant CPAP of $0.4 \mathrm{kPa}$ is applied for a $5 \mathrm{~min}$ period. Assuming that the patient is still awake during this time, the mean FOT value obtained within this period is considered to represent an individual "normal value", corresponding to a wake state without sleep-related upper airway obstruction. During the following treatment period, increasing values of this FOT signal are considered to represent dynamic upper airway obstruction. Thus when the actual FOT value is $>160 \%$ of the individual "normal value" the CPAP starts increasing by $0.02 \mathrm{kPa} \cdot \mathrm{s}^{-1}$ until the FOT-signal has "normalized" again. When the FOT signal remains $\leq 160 \%$ of the individual "normal value" for some time, the CPAP is gradually reduced. The time delay to initiation of pressure reduction, and the rate of pressure reduction depends on the "pattern" of the FOT signal which had initiated the pressure increase. If, for example, the pressure increase has been initiated by a single short rise in the FOT signal, pressure reduction starts at a rate of $0.01 \mathrm{kPa} \cdot \mathrm{s}^{-1}$ without any delay as soon as the FOT value has "normalized". In the authors experience single short increments in the FOT signal are often artefacts and the prompt pressure reduction following such an event is intended to avoid a lengthy pressure elevation. If, for example, the pressure increase has been initiated by $>1$ increment of the FOT value of $>160 \%$ of the "normal value" within $50 \mathrm{~s}$, the pressure reduction starts after a delay of $120 \mathrm{~s}$ at a rate of $0.005 \mathrm{kPa} \cdot \mathrm{s}^{-1}$. Such a "cluster" of obstructive events occurs, for example, when the sleeper changes position from lateral to supine. In this situation the treatment pressure should not be reduced too quickly. When the FOT value falls $<90 \%$ of the individual normal value, a central apnoea or a major leakage are assumed, and the pressure remains unchanged until the FOT value has "normalized" again.

During this study the lower pressure limit was set to $0.4 \mathrm{kPa}$, the upper limit to $1.8 \mathrm{kPa}$. The device was set to increase the CPAP by a maximum of $0.02 \mathrm{kPa} \cdot \mathrm{s}^{-1}$. No individual adjustments were made.

For constant-pressure CPAP therapy an identical device operating in constant pressure mode without FOT measurements was used (Somnotron 4®), Weinmann, Hamburg, Germany). 
Table 1. - Sleep parameters measured in patients treated with both auto- and constant continuous positive airway pressure therapies

\begin{tabular}{|c|c|c|c|c|c|c|}
\hline & $\begin{array}{l}\text { Baseline } \\
\text { study }\end{array}$ & Auto-CPAP & $\begin{array}{c}\text { Constant } \\
\text { pressure CPAP }\end{array}$ & $\begin{array}{c}\text { Mean } \\
\text { difference }^{+}\end{array}$ & $\begin{array}{l}\text { 95\% CI for } \\
\text { differences }\end{array}$ & p-value \\
\hline AI & $\begin{array}{c}27.0 \pm 20.4 \\
(2.1-75.8)\end{array}$ & $\begin{array}{c}1.7 \pm 1.7 \\
(0.0-7.2)\end{array}$ & $\begin{array}{c}2.6 \pm 2.2 \\
(0.7-7.1)\end{array}$ & -0.9 & -0.03 to 1.8 & NS \\
\hline AHI & $\begin{array}{c}48.0 \pm 28.1 \\
(10.5-112.1)\end{array}$ & $\begin{array}{l}3.4 \pm 3.4 \\
(0.5-13.3)\end{array}$ & $\begin{array}{l}4.2 \pm 3.6 \\
(0.6-12.8)\end{array}$ & -0.8 & -0.7 to 2.1 & NS \\
\hline ODI & $\begin{array}{c}53.8 \pm 28.7 \\
(11.7-124.8)\end{array}$ & $\begin{array}{c}8.6 \pm 9.8 \\
(0.6-27.5)\end{array}$ & $\begin{array}{l}11.2 \pm 12.6 \\
(0.8-47.2)\end{array}$ & -2.6 & -0.5 to 1.5 & NS \\
\hline Arousal index & $\begin{array}{l}28.8 \pm 13.5 \\
(8.0-61.7)\end{array}$ & $\begin{array}{l}6.6 \pm 2.1 \\
(2.3-10.2)\end{array}$ & $\begin{array}{l}7.3 \pm 4.4 \\
(1.4-18.0)\end{array}$ & -0.7 & -1.0 to 2.4 & NS \\
\hline TST min & $\begin{array}{r}347.6 \pm 29.2 \\
(300-392)\end{array}$ & $\begin{array}{r}345.1 \pm 33.3 \\
(279-416)\end{array}$ & $\begin{array}{r}336.6 \pm 41.1 \\
(230-386)\end{array}$ & -8.5 & -26.5 to 9.5 & NS \\
\hline Sleeping in supine position $\% \mathrm{TST}$ & $\begin{array}{l}45.4 \pm 24.0 \\
(1.9-100.0)\end{array}$ & $\begin{array}{c}65.0 \pm 28.6 \\
(14.5-98.9)\end{array}$ & $\begin{array}{l}62.1 \pm 26.1 \\
(17.0-100.0)\end{array}$ & -2.9 & -12.2 to 6.4 & NS \\
\hline Stage I + II \%TST & $\begin{array}{c}83.0 \pm 11.8 \\
(60.5-100.0)\end{array}$ & $\begin{array}{l}59.6 \pm 8.2 \\
(46.2-72.3)\end{array}$ & $\begin{array}{c}61.8 \pm 10.2 \\
(45.0-78.3)\end{array}$ & -2.6 & -1.4 to 6.4 & NS \\
\hline Stage III + IV \%TST & $\begin{array}{l}5.2 \pm 5.7 \\
(0.0-17.5)\end{array}$ & $\begin{array}{l}19.3 \pm 6.6 \\
(9.0-29.1)\end{array}$ & $\begin{array}{l}18.4 \pm 7.2 \\
(5.1-32.7)\end{array}$ & 0.9 & -2.8 to 1.1 & NS \\
\hline REM \%TST & $\begin{array}{l}11.8 \pm 7.3 \\
(0.0-23.0)\end{array}$ & $\begin{array}{l}21.7 \pm 4.9 \\
(14.3-32.2)\end{array}$ & $\begin{array}{l}19.8 \pm 6.8 \\
(7.3-30.9)\end{array}$ & 1.9 & -5.0 to 1.7 & NS \\
\hline ESS & $\begin{array}{r}13.3 \pm 3.0 \\
(10-19)\end{array}$ & $\begin{array}{c}5.6 \pm 1.8 \\
(3.0-9.0)\end{array}$ & $\begin{array}{c}5.3 \pm 1.6 \\
(3.0-8.0)\end{array}$ & 0.3 & -1.1 to 0.5 & NS \\
\hline Mean CPAP kPa & - & $\begin{array}{c}0.84 \pm 0.26 \\
(0.52-14.3)\end{array}$ & $\begin{array}{c}0.93 \pm 0.16 \\
(0.60-1.2)\end{array}$ & -0.09 & -0.006 to -0.19 & $\mathrm{p}=0.038$ \\
\hline
\end{tabular}

${ }^{+}$: Mean difference between corresponding values of auto-CPAP and constant CPAP therapy. Values are represented as mean \pm SD (range in brackets). 95\% CI: 95\% confidence interval; AI: apnoea index (number of apnoeas $\cdot \mathrm{h}^{-1}$ ); AHI: apnoea/hypopnoea-index (number of apnoeas and hypopnoeas $\cdot \mathrm{h}^{-1}$ ); ODI: oxygen desaturation index (number of desaturations $\geq 4 \%$ ); TST: total sleep time; \%TST: percentage of total sleep time; ESS: Epworth Sleepiness Scale; CPAP: continuous positive airway pressure. Ns: not significant.

\section{Study design}

In all patients, manual CPAP titrations were performed under polysomnographic control by trained sleep laboratory technicians as previously published [20]. The CPAP pressure was set to the lowest level which was found to be effective in preventing all signs of upper airway obstruction during all stages of sleep and in all body positions using the constant-pressure CPAP device. Starting from an initial $0.4 \mathrm{kPa}$, the pressure was increased in steps of $0.1 \mathrm{kPa}$ at intervals of at least 5 min when obstructive events (apnoeas, hypopnoeas, snoring or flow-limitation followed by arousal) occurred. If no further obstructive events occurred during a period of $30 \mathrm{~min}$, the pressure was reduced again at $10 \mathrm{~min}$ intervals in steps of $0.1 \mathrm{kPa}$ until such events reccurred, whereupon the pressure was increased once more in the manner described. If titration failed to reliably establish the minimal effective pressure (e.g. if not all the sleep stages could be studied) titration was repeated the following night. During the following two nights, patients were randomized to treatment either with the auto-CPAP machine or the constant-pressure device set to the effective CPAP established previously. Both treatments were performed under polysomnographic control. On the first night, 10 patients were allocated to conventional constant-pressure CPAP, the other 8 patients to autoCPAP (table 1). On the second night, each patient was switched to the other machine (cross-over design). During the study nights the technicians made no adjustments to the pressure titration algorithm of the auto-CPAP device nor did they attempt to correct minor air leaks. Only if a

Table 2. - Effect of body position and sleep stage on mean auto- continuous positive airway pressure

\begin{tabular}{|c|c|c|c|c|c|c|}
\hline $\begin{array}{l}\text { Number of } \\
\text { subjects }\end{array}$ & $\begin{array}{l}\text { Body position/ } \\
\text { sleep stage }\end{array}$ & $\begin{array}{l}\text { Mean CPAP } \\
\text { (range) kPa }\end{array}$ & $\begin{array}{l}\text { Body position/ } \\
\text { sleep stage }\end{array}$ & $\begin{array}{l}\text { Mean CPAP } \\
\text { (range) } \mathrm{kPa}\end{array}$ & $\begin{array}{l}\text { Mean difference } \\
\quad(95 \% \mathrm{CI})\end{array}$ & p-value \\
\hline $12 *$ & Supine & $\begin{array}{c}0.89 \pm 0.26 \\
(0.53-1.42)\end{array}$ & Lateral & $\begin{array}{c}0.74 \pm 0.35 \\
(0.50-1.51)\end{array}$ & $0.15(0.01-0.30)$ & 0.038 \\
\hline 18 & Awake & $\begin{array}{c}0.75 \pm 0.18 \\
(0.52-1.12)\end{array}$ & During sleep & $\begin{array}{c}0.84 \pm 0.26 \\
(0.52-1.46)\end{array}$ & $0.09(-0.20-0.02)$ & NS \\
\hline 18 & $\begin{array}{l}\text { Awake before } \\
\text { sleep onset }\end{array}$ & $\begin{array}{c}0.74 \pm 0.19 \\
(0.52-1.08)\end{array}$ & $\begin{array}{c}\text { Awake after } \\
\text { sleep onset }\end{array}$ & $\begin{array}{c}0.76 \pm 0.19 \\
(0.59-1.12)\end{array}$ & $-0.02(-0.12-0.06)$ & NS \\
\hline 18 & $\mathrm{I} / \mathrm{II}$ & $\begin{array}{c}0.87 \pm 0.28 \\
(0.53-1.46)\end{array}$ & III/IV & $\begin{array}{c}0.86 \pm 0.30 \\
(0.52-1.41)\end{array}$ & $0.01(-0.05-0.7)$ & NS \\
\hline 18 & REM & $\begin{array}{c}0.72 \pm 0.23 \\
(0.45-1.39)\end{array}$ & NREM & $\begin{array}{c}0.87 \pm 0.28 \\
(0.57-1.46)\end{array}$ & $-0.15(-0.21--0.08)$ & $<0.001$ \\
\hline
\end{tabular}

*: 6 patients slept only in the supine position. CPAP: continuous positive airway pressure. CI: confidence interval; REM: rapid eye movement; NREM: nonrapid eye movement; NS: not significant. 
patient woke because of major air leakage, was the mask repositioned and the CPAP device re-started.

After each of the two nights of treatment, the patients were asked to complete a questionnaire containing visual analogue scales covering various aspects of treatment quality, and to indicate which of the devices they would prefer for long-term treatment at home (table 2). They were also required to assess their actual daytime sleepiness with the aid of the ESS [13, 21].

The study protocol was examined and approved by the Ethics Committee of the Friedrich-Alexander University, Erlangen-Nuremberg.

\section{Data collection and statistical analysis}

The investigator entrusted with the evaluation of the polysomnographic tracings (F.S.F.) did not know whether the patient had been treated with conventional constantpressure CPAP or with auto-CPAP. The patients were also not aware of the sequence in which the two machines were used, and the machines in the laboratory were out of their sight.

All figures are expressed as arithmetic mean \pm standard deviation (SD). Group comparisons were performed using the paired t-test, Fisher's exact test, the Mann-Whitney Utest or the McNemar test where appropriate. The statistical calculations were performed with the aid of SPSS (version 6.0.1; SPSS Inc., Chicago, IL, USA). For differences between groups, a two-tailed $p$-value of $<0.05$ was considered significant.

\section{Results}

The study group comprised of 18 male patients with a mean age of $50.6 \pm 10.5$ yrs (31-69 yrs) and a mean body mass index (BMI) of $30.9 \pm 6.2 \mathrm{~kg} \cdot \mathrm{m}^{2}(22.7-48.7$ (table 1)). All 18 patients were studied in accordance with the protocol, with no drop-outs. There were no statistically significant differences found between the group receiving auto-CPAP first and the group starting with constant CPAP.

During auto-CPAP treatment, the mean AHI was 3.4 \pm 3.4 and thus did not differ significantly from that observed

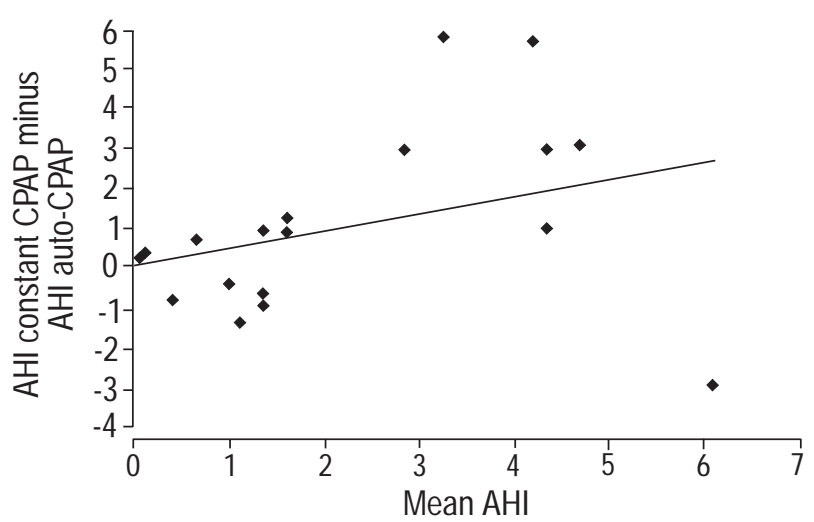

Fig. 1. - Apnoea/hypopnoea indices (AHI) obtained with auto-CPAP and constant CPAP therapy (Bland-Altman-Plot with regression line). CPAP: continuous positive airway pressure.

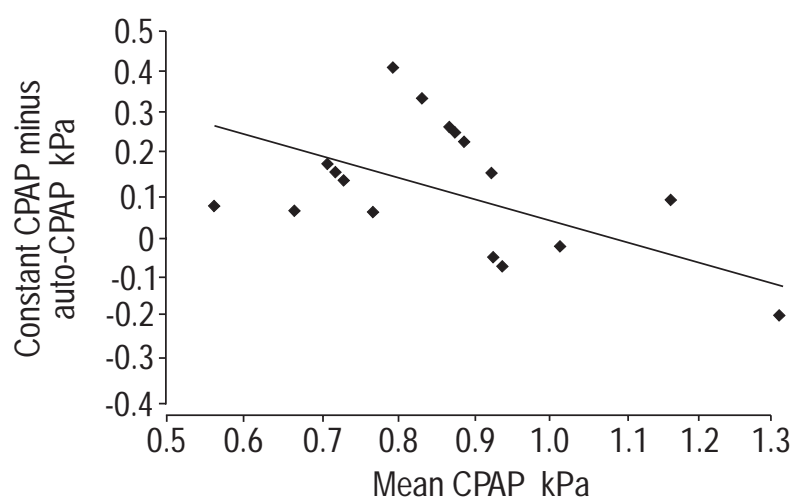

Fig. 2. - Mask pressure during constant-pressure CPAP therapy and mean CPAP during auto-CPAP treatment. CPAP: continuous positive airway pressure.

under conventional CPAP (4.2 \pm 3.6$)$. Both auto-CPAP and conventional CPAP decreased the AHI to a maximum of 10 in 17 of the 18 patients (fig. 1). During both forms of treatment polysomnographic analysis of the sleep architecture revealed largely normal sleep profiles, with no significant differences between the two treatment modes. No differences were also seen in terms of the number of arousals (table 1).

In 13 patients the mean treatment pressure during auto-CPAP therapy was lower than the corresponding constant-CPAP, in 5 patients it was higher (fig. 2). The mean pressure during auto-CPAP was $0.84 \pm 0.26 \mathrm{kPa}$, and was thus significantly lower than that during conventional CPAP $(0.93 \pm 0.16 \mathrm{kPa} ; \mathrm{p}=0.038$; mean difference $0.09 \mathrm{kPa}$; confidence interval $(\mathrm{CI})=-0.006-0.19$ $\mathrm{kPa}$; table 1). In some patients visual analysis of the recordings revealed marked reductions in auto-CPAP when the patients were lying on their sides (fig. 3) and the mean auto-CPAP applied in this position was $0.15 \mathrm{kPa}$ lower than that applied in the supine position $(0.74 \pm 0.35$ $\mathrm{kPa}$ versus $0.89 \pm 0.26 \mathrm{kPa} ; 95 \%$ CI for the mean difference $=-0.01--0.30 \mathrm{kPa} ; \mathrm{p}=0.036$; table 2 ). The mean auto-CPAP during rapid eye movement (REM) sleep was significantly lower than that during nonrapid eye movement (NREM) sleep $(0.72 \pm 0.23$ versus $0.87 \pm 0.28 \mathrm{kPa}$; mean difference $0.15 \mathrm{kPa} ; 95 \% \mathrm{CI}=-0.21--0.08$; $\mathrm{p}<0.001$; table 2).

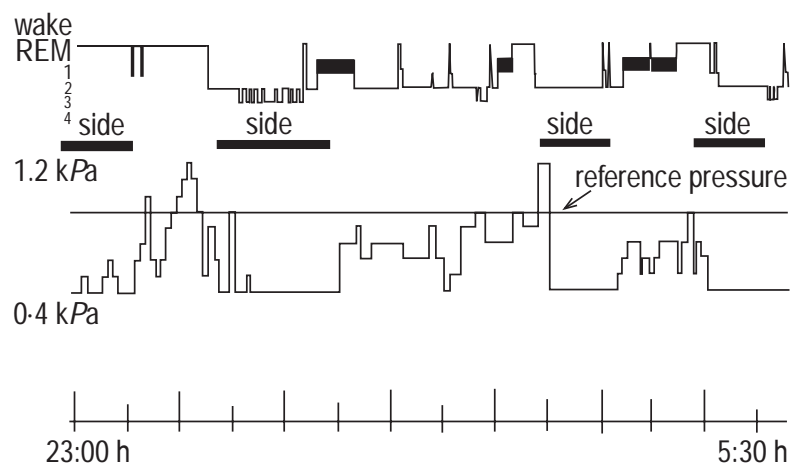

Fig. 3. - Autocontinuous positive airway pressure profile in a patient with marked pressure reductions when lying on the side (-). - - - : reference pressure; REM: rapid eye movement. 
Table 3. - The patients' evaluation of auto- and constant-continuous positive airway pressure treatment (questionnaire)

\begin{tabular}{|c|c|c|c|c|c|}
\hline \multirow{2}{*}{ Question } & \multicolumn{5}{|c|}{ Subject responser* } \\
\hline & 1 & 2 & 3 & 4 & 5 \\
\hline \multicolumn{6}{|c|}{ Were you disturbed by the noise or vibration of the machine? } \\
\hline constant CPAP & 0 & 0 & 0 & 9 & 9 \\
\hline \multicolumn{6}{|l|}{ How well did you sleep? } \\
\hline auto-CPAP & 0 & 1 & 4 & 13 & 0 \\
\hline constant CPAP & 0 & 4 & 3 & 11 & 0 \\
\hline \multicolumn{6}{|l|}{ Was the pressure unpleasantly high? } \\
\hline auto-CPAP & 0 & 0 & 2 & 8 & 8 \\
\hline constant CPAP & 0 & 0 & 0 & 9 & 9 \\
\hline \multicolumn{6}{|c|}{ How often did the treatment wake you up? } \\
\hline auto-CPAP & 0 & 1 & 4 & 12 & 1 \\
\hline constant CPAP & 0 & 1 & 4 & 11 & 2 \\
\hline \multicolumn{6}{|c|}{ Did you have to breathe against the machine? } \\
\hline auto-CPAP & 0 & 0 & 4 & 10 & 4 \\
\hline constant CPAP & 0 & 0 & 1 & 7 & 10 \\
\hline Which treatment would you prefer? & 8 & & 5 & & 5 \\
\hline
\end{tabular}

*: the scales correspond to: 1 : extremely; and 5 : not at all; 1 : very badly; and 5: very well; 1 : very often; and 5: never; 1 : I could not sleep at all; and 5: never; 1: very often; and 5: never; 1: auto-CPAP; 3: undecided; and 5: constant CPAP; for each of the questions respectively. CPAP: continuous positive airway pressure.

The ESS showed reduced scores for both treatment modes (table $1 ; \mathrm{p}<0.001$ versus baseline scores for both treatment modes), indicating less daytime sleepiness in all patients. No differences were seen between the two machines.

The majority of patients reported not feeling particularly disturbed by the noise or vibrations produced by either of the devices (table 3). For both machines, most of the patients assessed the quality of sleep to be good, and the treatment pressure to be acceptable, and reported arousal only rarely. Nevertheless, there was a tendency to report "breathing against the machine" more often after autoCPAP than after conventional CPAP therapy. No significant differences were found in the subjective evaluation of the two machines. Eight patients (44\%) indicated a preference for the auto-CPAP device for long-term use at home, while 5 patients $(28 \%)$ opted in favour of the conventional constant-pressure CPAP machine (NS) and 5 patients remained undecided (table 3 ).

\section{Discussion}

Although this study was designed on a double-blind basis, the possibility that either before falling asleep, or during nocturnal wake phases, some patients might have become aware of the automatic pressure adjustments carried out by the auto-CPAP machine or might have noted the vibrations of the FOT-unit cannot be excluded. However, since the patients were not informed about the rationale underlying the study, it may nevertheless be assumed that the subjective assessment of the devices would have been largely unbiased.

In the present study, only a single night of treatment with the auto-CPAP device was compared with a single night of treatment with constant-pressure CPAP. Considering the known spontaneous night-to-night variability in sleep architecture and the severity of OSA [22], the study design is not suitable for the detection of small differences between the two treatment modes. The aim of this study was to gain an initial orientation on the therapeutic effectiveness of the device investigated, before it is used in a larger series of patients.

When using the auto-CPAP device, the oscillating flow generated by the FOT-unit is superimposed to the respiratory flow. To ensure blinding of the investigator analyzing the polysomnographies, these oscillations had to be removed by a $20 \mathrm{~Hz}$-filter applied to the flow signal. Since such filtering has no significant impact on the total amplitude of the respiratory flow signal (which has a much lower frequency), apnoeas and hypopnoeas could still be precisely scored. Nevertheless, a $20 \mathrm{~Hz}$-filter may alter the shape of the flow signal to partially hide the signs of inspiratory flow-limitation ("flattening"). Thus an index of flow-limitation during the study nights could not be reliably obtained.

Beyond these potential limitations, the study shows that the auto-CPAP device driven exclusively by the forced oscillation technique is capable of achieving therapeutic results that are equally as good as those obtained with conventional CPAP therapy without any individual adjustments of the settings of the auto-CPAP device. This favourable therapeutic effect was achieved despite the fact that the mean treatment pressure applied by the auto-CPAP device was significantly lower than the corresponding constant CPAP pressure. The treatment pressure applied when the patient was sleeping in the lateral position was markedly lower than the corresponding constant CPAP pressure. This observation in particular indicates that the auto-CPAP device tested here is capable of matching the treatment pressure to the patients' Pcrit.

The pressure applied during REM sleep was reduced in comparison with NREM sleep. This observation conflicts the experience gained with other auto-CPAP devices which usually show a pressure reduction during slow wave sleep (Stages III and IV) [23]. Conversely, visual inspection of the recordings showed that the pressure reduction observed in REM sleep was not associated with an increase in the occurrence of apnoeas, hypopnoeas or 
arousals. The design of the present study did not allow the authors to establish the reason for this phenomenon. While a reduction in treatment pressure was obtained during sleep, it was occasionally observed that inappropriately high pressures were applied during nocturnal wake periods. As a consequence, the mean pressure during wakefulness was strikingly high (table 2). Some individual observations appear to indicate that such inappropriate pressure increases might be a consequence of coughing or speaking for example. Such movements involving the upper airways are associated with temporary reductions in the upper airway diameters and may lead to an increase in the FOT signal and thus may trigger inappropriate pressure increases. Since these "artefacts" occur only during wakefulness, they could theoretically be avoided by the patient. However, inappropriate pressure increases during wakefulness may be recognized by the patient and may thus lead to rejection of the treatment.

Theoretically, it would be expected that major leakages in the CPAP system could result in a degradation of the FOT signal, so that upper airway obstructions might then not be detected and pressure would be reduced despite of apnoeas, hypopnoeas or snoring. In this study, however, no such observations were made. This may be due to the wellcontrolled conditions of CPAP usage within the sleep laboratory, where major leakages can be avoided.

The use of FOT during nasal CPAP therapy makes it necessary to feed an additional oscillating pressure signal into the CPAP system. Theoretically, this oscillation might disturb the patients' sleep. On being questioned, however, none of the patients felt particularly disturbed, either by the noise produced by the system, or by vibrations. This is probably due to the very low amplitude of the pressure oscillations, which are only just appreciable by the wake patient. This is in accordance with observations of BADIA et al. [8] who reported no significant impairment of their patients sleep, when FOT was applied.

HeNKE et al. [24] studied the effects of high-frequency oscillating pressures on upper airway muscle activity and upper airway patency, and they were able to demonstrate that pressure oscillations applied for brief periods at the midpoint of central apnoeas could stimulate respiratory efforts in some patients. They also showed that $30 \mathrm{~Hz}$ pressure oscillations applied for the length of a single breath could stimulate genioglossus, sternomastoid and diaphragm EMG activity, and found that this could be associated with a reversal of upper airway obstruction [25]. Thus it may be speculated that the $20 \mathrm{~Hz}$ pressure oscillations applied by the auto-CPAP device in this study could have stimulated upper airway dilator muscles and in doing so might have lowered the effective CPAP pressure level. The possibility that such mechanisms might to some extent apply during FOT auto-CPAP treatment cannot be completely ruled out, but in contrast to the studies just mentioned, the pressure oscillations during FOT auto-CPAP had a significantly lower amplitude and were applied continuously all night. Nevertheless, this point should be addressed in further studies comparing the effective pressure level during CPAP with and without FOT measurements.

The pressure-saving effect of the auto-CPAP device was not equal for all patients. Some patients even had a higher mean CPAP on the auto-CPAP device than under conventional CPAP treatment. In some patients pressure saving is very pronounced; up to $0.4 \mathrm{kPa}$. Such savings occurred in particular when the patients were sleeping in a lateral position. This suggests that the device studied here might represent an alternative to conventional CPAP therapy in particular in such patients with a distinctly position-dependent sleep apnoea syndrome. This question should receive particular attention in further studies. No adjustments were made to the control parameters of the auto-CPAP device. For many of the auto-CPAP devices investigated so far, however, it has been shown that the results of treatment could be improved, for example, by setting upper and lower pressure limits. Further studies should therefore, be carried out to establish whether the treatment with this auto-CPAP device could be further improved, for example, by setting an upper pressure limit.

To conclude, the present study showed that an autocontinuous positive airway pressure device driven exclusively by the forced oscillation technique is capable of achieving a therapeutic effect comparable with that obtained with conventional continuous positive airway pressure therapy with no individual adjustment of the control parameters needed. At the same time, the mean treatment pressure is distinctly lower than that required with conventional continuous positive airway pressure treatment, especially in patients with position-dependent sleep apnoea syndrome. These data provide a promising basis for further studies using this device in a larger series of patients.

\footnotetext{
Acknowledgements. The authors would like to thank M. Mueller for her organizational support. The auto-CPAP devices used during this study were provided, free of charge, by Weinmann $\mathrm{GmbH}$, Hamburg, Germany.
}

\section{References}

1. Sullivan CE, Issa FG, Berthon Jones M, Eves L. Reversal of obstructive sleep apnoea by continuous positive airway pressure applied through the nares. Lancet 1981; 1: 862865.

2. Milijeteig H, Hoffstein V. Determinants of continuous positive airway pressure level for treatment of obstructive sleep apnea. Am Rev Respir Dis 1993; 147: 1526-1530.

3. Sforza E, Krieger J, Bacon W, Petiau C, Zamagni M, Boudewijns A. Determinants of effective continuous positive airway pressure in obstructive sleep apnea. Role of respiratory effort. Am J Respir Crit Care Med 1995; 151: 1852-1856.

4. Pevernagie DA, Shepard JWJ. Relations between sleep stage, posture and effective nasal CPAP levels in OSA. Sleep 1992; 15: 162-167.

5. Series F, Marc I, Cormier Y, La Forge J. Required levels of nasal continuous positive airway pressure during treatment of obstructive sleep apnea. Eur Respir J 1994; 7: 1776-1781.

6. Grunstein RR. Sleep-related breathing disorders. 5. Nasal continuous positive airway pressure treatment for obstructive sleep apnea. Thorax 1995; 50: 1106-1113.

7. Reisch S, Schneider M, Timmer J, Geiger K, Guttmann J. Evaluation of forced oscillation technique for early detection of airway obstruction in sleep apnea: a model study. Technol Health Care 1998; 6: 245-257.

8. Badia JR, Farre R, Montserrat JM, et al. Forced oscillation technique for the evaluation of severe sleep apnea/ 
hypopnea syndrome: a pilot study. Eur Respir J 1998; 11: $1128-1134$.

9. Rühle KH, Schlenker E, Randerath W. Upper airway resistance syndrome. Respiration 1997; 64: 29-34.

10. Ficker JH, Wiest GH, Asshoff G, Fuchs FS, Harsch IA, Hahn EG. Sensitivity of a simplified forced oscillation technique for detection of upper airway obstruction. Respir Physiol 2000.

11. Navajas D, Farre R, Rotger M, Badia R, Puig-de-Morales M, Montserrat JM. Assessment of airflow obstruction during CPAP by means of forced oscillation in patients with sleep apnea. Am J Respir Crit Care Med 1998; 157: 1526-1530.

12. Reisch S, Steltner H, Timmer J, Renotte C, Guttmann J. Early detection of upper airway obstructions by analysis of acoustical respiratory input impedance. Biol Cybern 1999; 81: 25-37.

13. Johns MW. A new method for measuring daytime sleepiness. The Epworth Sleepiness Scale. Sleep 1991; 14: 540-545.

14. American Thoracic Society: Indications and standards for use of nasal continuous positive airway pressure (CPAP) in sleep apnea syndromes. Am J Respir Crit Care Med 1994; 150: 1738-1745.

15. Gould GA, Whyte GB, Airlie MAA, Catterall JR, Shapiro CM, Douglas NJ. The sleep hypopnea syndrome. Am Rev Respir Dis 1988; 137: 895-898.

16. Rechtschaffen A, Kales A. A Manual of Standardized Terminology, Techniques and Scoring System for Sleep Stages of Human Subjects. Public Health Service, US Government Printing, 1968; pp. 1-12.
17. Bonnet M, Carley D, Carskadon MA. EEG arousals: scoring rules and examples. Sleep 1992; 15: 174-184.

18. Reisch S, Renotte C, Timmer J, Honerkamp J, Geiger K, Guttmann J. Theoretische Evaluierung der Resisto-Oszillometrie bei obstruktiver Schlafapnoe. Biomedizinische Technik 1996; 41: 108-109.

19. Reisch S, Kulstrunk M, Timmer J, et al. Physikalisches Modell zur Simulation von Zeitverläufen der Atemwegsimpedanz bei obstruktiver Schlafapnoe. Biomedizinische Technik 1996; 41: 84-85.

20. Ficker JH, Wiest GH, Lehnert G, Wiest B, Hahn EG. Evaluation of an auto-CPAP device for treatment of obstructive sleep apnea. Thorax 1998; 53: 643-648.

21. Hardinge FM, Pitson DJ, Stradling JR. Use of the Epworth Sleepiness Scale to demonstrate response to treatment with nasal continuous positive airways pressure in patients with obstructive sleep apnea. Respiratory Medicine 1995; 89: 617-620.

22. Meyer TJ, Eveloff SE, Kline LR, Millman RP. One negative polysomnogram does not exclude obstructive sleep apnea. Chest 1993; 103: 756-760.

23. Meurice JC, Marc I, Series F. Efficacy of auto-CPAP in the treatment of obstructive sleep apnea/hypopnea syndrome. Am J Respir Crit Care Med 1996; 153: 794-798.

24. Henke KG, Sullivan CE. Effects of high-frequency pressure waves applied to upper airway on respiration in central apnea. J Appl Physiol 1992; 73: 1141-1145.

25. Henke KG, Sullivan CE. Effects of high-frequency oscillating pressures on upper airway muscles in humans. $J$ Appl Physiol 1993; 75: 856-862. 